\title{
Arthroscopic treatment of refractory adhesive capsulitis of the shoulder
}

\section{Tratamento artroscópico da capsulite adesiva refratária do ombro}

\author{
Marcos Rassi Fernandes ${ }^{1}$
}

A B S T R A C T

\begin{abstract}
Objective: to evaluate the results of arthroscopic treatment of refractory adhesive capsulitis of the shoulder associated as for improved range of motion after a minimum follow up of six years. Methods: from August 2002 to December 2004, ten patients with adhesive capsulitis of the shoulder resistant to conservative treatment underwent arthroscopic surgery. One interscalene catheter was placed for postoperative analgesia before the procedure. All were in Phase II, with a minimum follow up of two years. The mean age was 52.9 years (39-66), predominantly female (90\%), six on the left shoulder. The time between onset of symptoms and surgical treatment ranged from six to 20 months. Four adhesive capsulitis were found to be primary (40\%) and six secondary (60\%). Results: the preoperative mean of active anterior elevation was $92^{\circ}$, of external rotation was $10.5^{\circ}$ of the $L 5$ level internal rotation; the postoperative ones were $149^{\circ}, 40^{\circ}$ and T12 level, respectively. Therefore, the average gain was $57^{\circ}$ for the anterior elevation, $29.5^{\circ}$ for external rotation in six spinous processes. There was a significant difference in movements' gains between the pre and post-operative periods $(p<0.001)$. By the Constant Score (range of motion), there was an increase of 13.8 (average pre) to 32 points (average post). Conclusion: the arthroscopic treatment proved effective in refractory adhesive capsulitis of the shoulder resistant to conservative treatment, improving the range of joint movements of patients evaluated after a minimum follow up of six years.
\end{abstract}

Key words: Bursitis. Shoulder pain. Surgical procedures, operative. Arthroscopy. Orthopedics.

\section{INTRODUCTION}

A dhesive capsulitis (AC), frozen shoulder, stiff shoulder and retractable capsulitis are terms used to denote the condition of pain and stiffness of the glenohumeral joint to active and passive movements. This condition of rigidity has very diverse etiology, being installed primarily, or idiopathic, secondary to systemic diseases, such as diabetes mellitus, hypothyroidism, or even subsequent to shoulder trauma or operation ${ }^{1-3}$.

It is known that AC is benign and self-limited, and resolves spontaneously in around two years ${ }^{3}$, but some patients remain symptomatic, with severe movement restriction, even after several years of disease onset ${ }^{2}$.

It causes great disability, and many are its treatments ${ }^{3,4}$. Most patients respond adequately to conservative of clinical treatment ${ }^{3,4}$, joint injections ${ }^{5}$, manipulations ${ }^{6}$, the anesthetic blockades ${ }^{7,8}$ and/or physical therapy ${ }^{9}$. The duration of conservative treatment for $A C$ has been discussed, but it is recommended that it be done for at least six months ${ }^{3}$. Some patients do not respond adequately to these therapeutic modalities, requiring open ${ }^{10}$ or arthroscopic ${ }^{6,11,12}$ surgery.

Arthroscopy has proven very effective in the treatment of $\mathrm{AC}$ by combining minimal tissue trauma and great view of the shoulder joint for capsular release ${ }^{11,12}$. The hypothesis was that the treatment under arthroscopic view would lead to a significant improvement in the gain of joint movements.

Thus, we evaluated the results of arthroscopic treatment of shoulder refractory $A C$ associated with improved range of joint movements after a minimum followup of six years.

\section{METHODS}

This was a retrospective study of patients with adhesive capsulitis of the shoulder, refractory to conservative treatment, undergoing arthroscopic surgery between August 2002 and December 2004.

The study protocol was approved by the Ethics Committee on Human and Animal Research of the Goiânia General Hospital (477-2009).

We previously defined patients with "refractory adhesive capsulitis of the shoulder" as with: presence of constant and intense pain (zero points on the Constant pain scale functional index); no improvement with conservative treatment for at least six months; limited range of active and passive motion of the shoulder, the anterior elevation

1. Department of Orthopaedics and Traumatology, Faculty of Medicine, Federal University of Goiás - UFG, Goiânia, Goiás State - GO, Brazil. 
being up to $130^{\circ}$, the external rotation up to $50^{\circ}$, and the internal rotation up to $L 5$.

We retrospectively included in this series subjects that: were diagnosed with refractory AC; classified as stage II disease; had cognitive conditions to participate; were aged between 35 and 70 years; had been operated by the same surgeon and with minimum follow-up of two years. Patients with rotator cuff injury, instability, glenohumeral arthrosis and locked shoulder dislocation were excluded.

Preoperatively, all patients underwent physical therapy for a minimum period of six months; five of them were also submitted to suprascapular nerve block, and none to hydraulic distension or manipulation under narcosis.

Regarding radiographic evaluation, anteroposterior incidences with correction of anteversion of the scapula, axillary profile and scapular profile were performed.

The joint range of motion was measured preoperatively and postoperatively according to the criteria of the American Academy of Orthopaedics Surgeons ${ }^{13}$. We used the Constant index for functional assessment of the operated shoulder ${ }^{14}$. To classify the disease and its clinical severity, we used the classification of Zuckerman et al. ${ }^{15}$. The shoulder range of motion was the outcome variable.

The pre- and postoperative values were compared by t-paired parametric test, with the risk assumed by the researcher of $5 \%$ and probability of rejecting the null hypothesis less than 0.05 .

\section{Surgical Technique}

We installed an interscalene catheter for postoperative analgesia prior to each surgical procedure. Patients were placed in lateral decubitus position, with a longitudinal traction apparatus at $20^{\circ}$ flexion and abduction of the operated limb, and vertical to decoaptation of the glenohumeral joint with $5 \mathrm{~kg}$.

We used the posterior approach of the glenohumeral joint, two centimeters inferior and medially to the bottom of posterolateral acromion border. This access was hampered by the existing capsular retraction in this disease, demanding care not to injure the joint cartilage, both of the humeral head and of the glenoid.

After an inventory of the synovial joint, biceps tendon, humeral head capsule and rotator cuff, we inserted the anterosuperior portal (instrumentation portal), beside the tendon of the long head of the biceps, advancing the trocar through the rotator interval, inside-out, using a 8.25x7 mm cannula.

We initially held a synovectomy with $4.5 \mathrm{~mm}$ full radius blade, with subsequent opening of the rotator interval, the anterior edge of the supraspinatus to the superior border of the subscapularis and subsequent release of the coracohumeral ligament, which was identified on palpation of the coracoid process with a probe (Figure 1).

Then, using electrocautery or radiofrequency instrument, we held the tenotomy of the subscapularis tendon (Figure 2), which was carefully separated from the middle glenohumeral ligament. The opening of the anterior capsule was carried out by freeing it from the upper edge to the lower edge of the glenoid. The optical was moved to the front trocar, and the instrument to the back for the release of the posterior capsule, along the edge of the glenoid from the rear of the biceps to position eight hours. The inferior capsule was released along its glenoid insertion to complete a circumferential capsulotomy. No manipulation was performed after surgery.

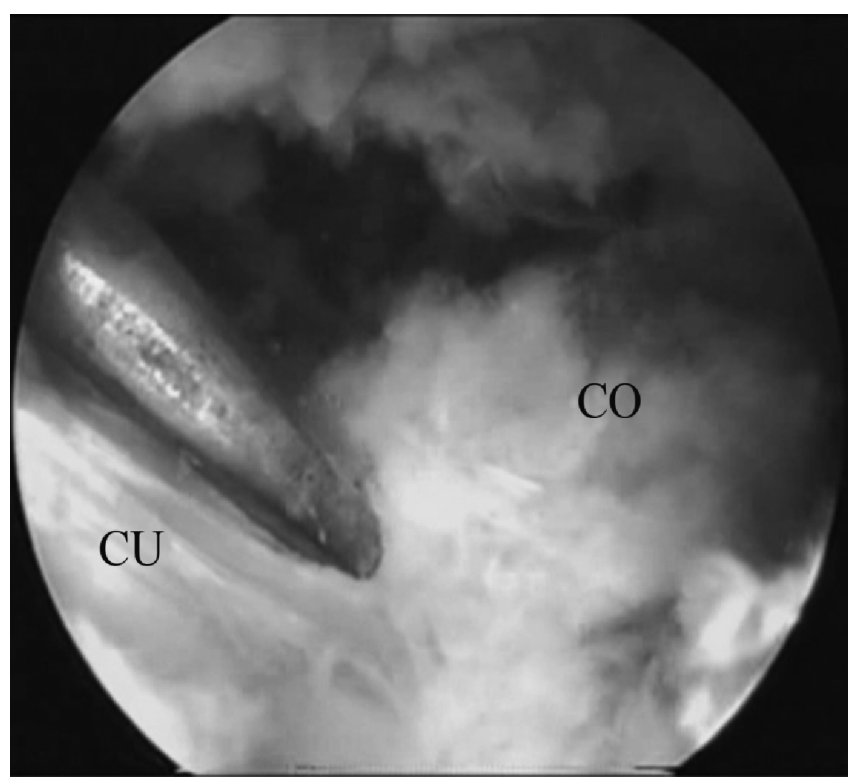

Figure 1 - Release of coracohumeral ligament.

Legend: CO - coracoid process; CU - coracohumeral ligament.

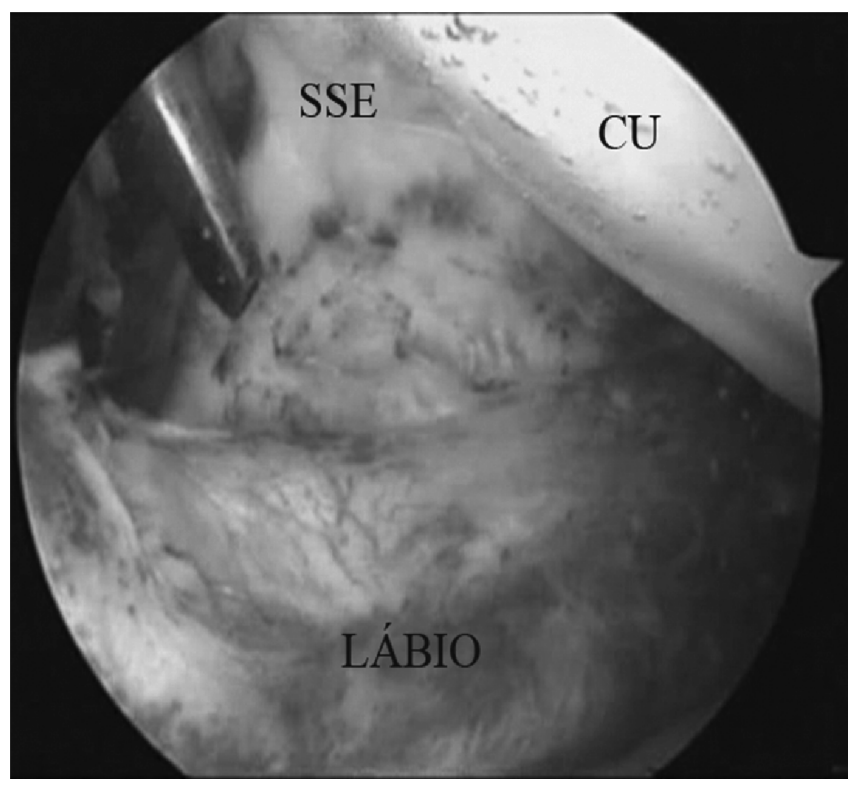

Figure 2 - Tenotomy of the subscapularis.

Legend: CU - humeral head; SSE - subscapularis tendon. 
Postoperatively, still in bed, patients underwent physical therapy twice a day, after infusion of 15 to $20 \mathrm{ml}$ of $0.5 \%$ bupivacaine in the interscalene catheter 30 minutes before each session. Admission for the immediate commencement of rehabilitation occurred for 72 hours and consisted of passive exercises of the shoulder in anterior elevation, external rotation, and internal rotation.

After discharge, patients remained without immobilization and were told to start supervised physical therapy five times a week and use the shoulder in daily activities.

\section{RESULTS}

Demographic data are shown in Table 1, and the surgical procedures performed, in Table 2. The time between onset of symptoms and operation ranged from six to 20 months, with an average of nine. The average hospital stay was three days.

The active preoperative averages were as follows: anterior elevation (AE) 92 ; external rotation (ER) at $90^{\circ}$ of elbow flexion; abduction $0^{\circ}$; internal rotation (IR) $10.5^{\circ}$ on $\mathrm{L} 5$ vertebral level. The active postoperative averages, on their turn, were: AE $149^{\circ}$; ER $40^{\circ}$ and $\mathrm{RI}$ at T12 vertebral level (Table 3). Therefore, average gains were $57^{\circ}$ for $A E, 29.5^{\circ}$ in for $E R$ and six spinous processes. As for the Constant evaluation (40 points), there was an increase from 13.8 (average pre) to 32 (average post). All patients showed decreased in the pain scale in the last assessment (absent or mild Constant). When comparing the averages, we observed a difference in the gains of movements between pre and postoperative periods, $\mathrm{p}<0.001$.

There were no intraoperative complications, instability or neurological injury.

\section{DISCUSSION}

Adhesive capsulitis of the shoulder is a common disease, but with an uncertain pathogenesis ${ }^{16}$. The histology shows a matrix of collagen types I and III, as populated by fibroblasts, suggesting that it is modulated by an abnormality in the production of growth factors and cytokines ${ }^{17}$. Thus, this cascade of inflammation involves abnormal tissue repair and fibrosis ${ }^{18}$.

Ozaki et al. reported that the contracture of the coracohumeral ligament and of the rotator interval seems to be the primary lesion in AC. The pathological findings of these structures are extremely important when approaching such patients ${ }^{19}$.

The disease occurs with greater predominance between 40 and 60 years of age in females and on the non-dominant side, without racial predilection $2,3,9$. The present study had a mean age of 52.9 years and $90 \%$ of women, which coincides with the literature data, although half the patients presenting with $\mathrm{AC}$ on the dominant side.

Hard shoulders respond well to non-surgical treatment in $70-90 \%$ of patients ${ }^{4}$. Lorbach et al. reported that the use of corticosteroids, both as intra-articular injections and as short-term oral administration, improved the range of motion and pain reduction ${ }^{20}$.

Another therapeutic option would be blocking the suprascapular nerve, which is an efficient method when compared with placebo and intra-articular injections ${ }^{21}$. The procedure is justified, since this nerve is responsible for $70 \%$ of the sensitivity of the shoulder capsule, which becomes retractile and with its volume diminished in $\mathrm{AC}^{3,7,8}$. However, five of the ten patients (50\%) underwent such a method, associated with physiotherapy measures, with no efficacy.

Manipulation under anesthesia has been effective, but does not allow a controlled release of the affected tissue, with increased risk of fractures of the

Table 1 - Demographic data.

\begin{tabular}{lcccccccccc}
\hline Cases & $\begin{array}{c}\text { A ge } \\
\text { (years) }\end{array}$ & Gender & Side & Dom & Form & SEC & EST & Grav & S-O(m) & FU (years) \\
\hline 1 & 66 & Fem & Left & No & PRIM & & $\|$ & severe & 06 & 9 \\
2 & 56 & Fem & Right & & SEC & PT & $\|$ & mod & 08 & 8 \\
3 & 59 & Fem & Left & No & SEC & PO & $\|$ & mod & 09 & 8 \\
4 & 39 & Fem & Right & No & SEC & PT & $\|$ & mod & 20 & 7 \\
5 & 64 & Male & Left & & SEC & DIAB & $\|$ & mod & 09 & 6 \\
6 & 47 & Fem & Left & & PRIM & & $\|$ & mild & 07 & 6 \\
7 & 45 & Fem & Right & No & SEC & HYPO & $\|$ & mod & 08 & 6 \\
8 & 50 & Fem & Left & & SEC & DIAB & II & mod & 07 & 7 \\
9 & 48 & Fem & Left & No & PRIM & & II & mild & 08 & 6 \\
10 & 55 & Fem & Right & & PRIM & & II & severe & 08 & 6 \\
\hline
\end{tabular}

Source: Medical Files

Fem: female; DOM: dominance; PRIM: primary; SEC: secondary, PO: postoperative, PT: post-trauma; DIAB: diabetes; HYPO: hypothyroidism; STG: stage of disease; GRAV: disease severity; mod: moderate, S-O: time between symptoms and operation; (M): months; FU: follow-up time. 
Table 2 - Procedures performed in the sample.

\begin{tabular}{lcccccc}
\hline Cases & Anterio C. & Superior C. & Posterior C. & Inferior C. & SSE tenotomy & Add proc \\
\hline 1 & Yes & Yes & No & No & Partial & Acromioplasty \\
2 & Yes & Yes & Yes & Yes & Partial & No \\
3 & Yes & Yes & Yes & Yes & Partial & No \\
4 & Yes & Yes & Yes & Yes & Total & Bursal synovectomy \\
5 & Yes & Yes & Yes & Yes & Partial & No \\
6 & Yes & Yes & Yes & Yes & Total & Total \\
7 & Yes & Yes & Yes & Yes & Total & No \\
8 & Yes & Yes & Yes & Yes & Total & No \\
9 & Yes & Yes & No & No & Total & No \\
10 & Yes & Yes & Yes & Yes & & \\
\hline
\end{tabular}

Source: Medical Files

C.: capsulotomy; SSE: subscapularis; ADD PROC: Additional procedures.

Table 3 - Pre and postoperative values shoulder of active range of MOTION.

\begin{tabular}{lcccc}
\hline Cases & AE Pre & ER Pre & AE Post & ER Post \\
\hline 1 & $70^{\circ}$ & $5^{\circ}$ & $180^{\circ}$ & $40^{\circ}$ \\
2 & $90^{\circ}$ & $30^{\circ}$ & $120^{\circ}$ & $40^{\circ}$ \\
3 & $90^{\circ}$ & $10^{\circ}$ & $180^{\circ}$ & $50^{\circ}$ \\
4 & $90^{\circ}$ & $0^{\circ}$ & $170^{\circ}$ & $40^{\circ}$ \\
5 & $100^{\circ}$ & $10^{\circ}$ & $120^{\circ}$ & $20^{\circ}$ \\
6 & $120^{\circ}$ & $40^{\circ}$ & $170^{\circ}$ & $50^{\circ}$ \\
7 & $100^{\circ}$ & $0^{\circ}$ & $170^{\circ}$ & $40^{\circ}$ \\
8 & $90^{\circ}$ & $10^{\circ}$ & $120^{\circ}$ & $50^{\circ}$ \\
9 & $110^{\circ}$ & $0^{\circ}$ & $170^{\circ}$ & $40^{\circ}$ \\
10 & $60^{\circ}$ & $0^{\circ}$ & $90^{\circ}$ & $30^{\circ}$ \\
Mean & $92^{\circ}$ & $10,5^{\circ}$ & $149^{\circ}$ & $40^{\circ}$ \\
\hline
\end{tabular}

Source: Medical Files

AE: anterior elevation, ER: external rotation, Pre: preoperative, Post: postoperative.

humerus ${ }^{3,5,6}$. Dodenhoff et al. reported that $94 \%$ of patients who had undergone manipulation were satisfied with their results, but $12.8 \%$ still had persistent failure ${ }^{22}$. Fox et al. showed that the manipulation resulted in sustained improvement in function and joint motion of the shoulder ${ }^{23}$. Due to the risk of complications of this treatment method, it was not performed in any patient of the series.

Surgical treatment of AC with capsular release should be reserved for patients who do not respond to conservative treatment for a minimum period of six months ${ }^{3}$, as applied in this study.

The exploration of the coracohumeral ligament demonstrates that it is the thickest and abnormal part of the capsule in $\mathrm{AC}^{10}$. For being an extra-articular anatomical structure, its arthroscopic release is only possible after the opening of the rotator interval and exposure of the lateral and inferior surface of the coracoid process. Its section is intended to restore external rotation and pain relief ${ }^{19}$.

This release step was performed in all patients in the study and the average gain of external rotation was $29.5^{\circ}$, unlike the study by Beaufils et al. who applied in only one of 26 patients and concluded that capsular release was of little benefit in primary AC, with long recovery time, not leading to pain relief ${ }^{24}$.

The subacromial fibrosis with synovial hypertrophy was observed in several studies, both the debridement and acromioplasty being performed to improve outcome ${ }^{25,26}$. Chen et al. reported that $86 \%$ of the patients underwent subacromial decompression, with contribution for the shoulder pain relief27. The capsular release was performed in two cases in this series, with two additional procedures, and with substantial pain relief in all cases. Having this not been a study of association between these variables, we cannot say that one has contributed to the improvement of the other.

In addition to anterior capsulotomy, there is controversy whether the posterior and inferior structures should or should not be released. Ogilvie-Harris et al. advocate the inferior release, but without the posterior one $^{28}$. Jerosch described his technique performing both ${ }^{25}$. 
Chen et al., in a 74 patients randomized study, submitted the first group to anterior capsulotomy, while in the second the release was extended to the posterior and inferior capsule. They concluded that function and range of motion of the shoulder were equivalent after six months ${ }^{27}$. Snow et al. also showed no differences when added the posterior release to the procedure ${ }^{11}$.

This study improved the range of motion of patients with the use of posterior and inferior release, except in two cases, regardless of the adhesive capsulitis being primary or secondary.

There is also the concern of axillary nerve injury in performing inferior capsulotomy. As it is closer to the humeral insertion of the capsule, the release must be done near the glenoid rim $^{25}$. None of the patients in this series had neuropraxia of the axillary nerve, the same as Jerosch ${ }^{25}$; Harryman et al., however, had one case of praxis, with spontaneous resolution ${ }^{29}$.

Pearsall et al. ${ }^{26}$ and Ogilvie-Harris et al..$^{28}$ reported the release of the intra-articular portion of the subscapularis, lateral muscle tendon junction, though most studies have shown excellent results without this step ${ }^{25,27,30}$. This portion represents only $25 \%$ of cephalocaudal length of the subscapularis muscle. For this reason and because it is an important opponent of external rotation, this procedure was added to the technique presented.

The realization of tenotomy allowed the lack of any type of joint manipulation postoperatively, which ends up being an advantage of the presented technique. It is important to mention that no postoperative relapse occurred. Did the tenotomy contributed to this? Since this was not a randomized clinical trial, this question remains unanswered.

It is important to know whether the section of the subscapularis would undermine the anterior stability of the shoulder. Pearsall et al. showed $97 \%$ of patients with minimal or no signs of instability ${ }^{26}$. There were no cases of anterior instability after arthroscopic surgery in this study, the tenotomy being partial or total.

Berghs et al. ${ }^{31}$ presented their results of arthroscopic treatment of $A C$, in which the mean anterior elevation improved from $73.7^{\circ}$ to $163^{\circ}\left(89.3^{\circ}\right)$, external rotation from $10.6^{\circ}$ to $46.8^{\circ}\left(36.2^{\circ}\right)$ and internal rotation in nine levels. In turn, Elhassan et al..$^{32}$ reported means increases for the same Rightections by $38^{\circ}, 24^{\circ}$ and six levels, respectively, similar to the present study, which showed an average improvement of $57^{\circ}$ in the anterior elevation, $29.5^{\circ}$ external rotation and six levels in internal rotation $(p<0.001)$.

Limitations of this study include being retrospective, non-comparative and having a small number of subjects in the sample design, since $A C$ is an inherently non-surgical disease and few patients evolve to surgical indication. This study, however, is important in the fact that it had the same surgical technique performed in all patients, regardless of the etiology of AC. The size of the groups, however, does not allow drawing conclusions in this regard.

In conclusion, the arthroscopic treatment was effective in refractory adhesive capsulitis of the shoulder resistant to conservative treatment, improving range of joint movements of patients evaluated after a minimum follow up of six years.

\title{
R E S U M O
}

\begin{abstract}
Objetivo: avaliar os resultados do tratamento artroscópico da capsulite adesiva refratária do ombro, relacionados à melhora da amplitude de movimentos, após seguimento mínimo de seis anos. Métodos: do período de agosto de 2002 a dezembro de 2004, dez pacientes com capsulite adesiva do ombro resistentes ao tratamento conservador foram submetidos à cirurgia artroscópica. Foi colocado um cateter interescalênico para analgesia pós-operatória, antes do procedimento. Todos se encontravam na Fase II, com seguimento mínimo de dois anos. A média de idade foi 52,9 anos (39 a 66), com predominância do sexo feminino (90\%), sendo seis ombros do lado esquerdo. O tempo entre o aparecimento dos sintomas e o tratamento operatório variou de seis a 20 meses. Foram encontradas quatro capsulites adesivas na forma primária (40\%) e seis secundárias (60\%). Resultados: a média ativa préoperatória da elevação anterior foi $92^{\circ}$, da rotação externa $10,5^{\circ}$ da rotação interna nível $L 5$ e a média ativa pós-operatória foi $149^{\circ}$, $40^{\circ}$ e nível T12, respectivamente. Portanto, os ganhos médios foram de $57^{\circ}$ na elevação anterior, $29,5^{\circ}$ na rotação externa e seis processos espinhosos. Houve diferença significativa nos ganhos de movimentos entre o pré e o pós-operatório ( $p<0,001)$. Pela pontuação de Constant (amplitude de movimentos), houve um aumento de 13,8 (média pré) para 32 pontos (média pós). Conclusão: o tratamento artroscópico mostrou-se eficaz na capsulite adesiva refratária do ombro, resistente ao tratamento conservador, melhorando a amplitude dos movimentos articulares de pacientes avaliados após seguimento mínimo de seis anos.
\end{abstract}

Descritores: Bursite. Dor de ombro. Procedimentos cirúrgicos operatórios. Artroscopia. Ortopedia.

\section{REFERENCES}

1. Zuckerman JD, Rokito A. Frozen shoulder: a consensus definition. J Shoulder Elbow Surg. 2011;20(2):322-5.

2. Hand C, Clipsham K, Rees JL, Carr AJ. Long-term outcome of frozen shoulder. J Shoulder Elbow Surg. 2008;17(2):231-6.
3. Tasto JP, Elias DW. Adhesive capsulitis. Sports Med Arthrosc. 2007;15(4):216-21.

4. Levine WN, Kashyap CP, Bak SF, Ahmad CS, Blaine TA, Bigliani LU. Nonoperative management of idiopathic adhesive capsulitis. J Shoulder Elbow Surg. 2007;16(5):569-73. 
5. Jacobs LG, Smith MG, Khan SA, Smith K, Joshi M. Manipulation or intra-articular steroids in the management of adhesive capsulitis of the shoulder? A prospective randomized trial. J Shoulder Elbow Surg. 2009;18(3):348-53

6. Massoud SN, Pearse EO, Levy O, Copeland SA. Operative management of the frozen shoulder in patients with diabetes. J Shoulder Elbow Surg. 2002;11(6):609-13.

7. Fernandes MR, Barbosa MA, Souza ALL, Ramos GC. Bloqueio do nervo supraescapular: procedimento importante na prática clínica. Rev Bras Anestesiol. 2012;62(1):100-4.

8. Checchia SL, Fregoneze M, Miyazaki AN, Santos PD, Silva LA, Ossada A, et al. Tratamento da capsulite adesiva com bloqueios seriados do nervo supra-escapular. Rev Bras Ortop. 2006;41(7):24552.

9. Ferreira Filho AA. Capsulite Adesiva. Rev Bras Ortop 2005;40(10):565-74.

10. Omari A, Bunker TD. Open surgical release for frozen shoulder: surgical findings and results of the release. J Shoulder Elbow Surg. 2001;10(4):353-7.

11. Snow M, Boutros I, Funk L. Posterior arthroscopic capsular release in frozen shoulder. Arthroscopy. 2009;25(1):19-23.

12. Baums MH, Spahn G, Nozaki M, Steckel H, Schultz W, Klinger HM. Functional outcome and general health status in patients after arthroscopic release in adhesive capsulitis. Knee Surg Sports Traumatol Arthrosc. 2007;15(5):638-44. Erratum in: Knee Surg Sports Traumatol Arthrosc. 2007;15(5):687.

13. American Academy of Orthopaedics Surgeons. Joint motion: method of measuring and recording. Chicago: American Academy of Orthopaedics Surgeons; 1965.

14. Constant CR, Murley AH. A clinical method of functional assessment of the shoulder. Clin Orthop Relat Res. 1987:(214):160-4.

15. Zuckerman JD, Cuomo F, Rokito S. Definition and classification of frozen shoulder: a consensus approach. J Shoulder Elbow Surg. 1994;3(1):S72.

16. Hand GC, Athanasou NA, Matthews T, Carr AJ. The pathology of frozen shoulder. J Bone Joint Surg Br. 2007;89(7):928-32.

17. Bunker TD, Reilly J, Baird KS, Hamblen DL. Expression of growth factors, cytokines and matrix metalloproteinases in frozen shoulder. J Bone Joint Surg Br. 2000;82(5):768-73.

18. Mullett $H$, Byrne D, Colville J. Adhesive capsulitis: human fibroblast response to shoulder joint aspirate from patients with stage II disease. J Shoulder Elbow Surg. 2007;16(3):290-4

19. Ozaki J, Nakagawa Y, Sakurai G, Tamai S. Recalcitrant chronic adhesive capsulitis of the shoulder. Role of contracture of the coracohumeral ligament and rotator interval in pathogenesis and treatment. J Bone Joint Surg Am. 1989;71(10):1511-5.

20. Lorbach O, Anagnostakos K, Scherf C, Seil R, Kohn D, Pape D. Nonoperative management of adhesive capsulitis of the shoulder: oral cortisone application versus intra-articular cortisone injections. J Shoulder Elbow Surg. 2010;19(2):172-9.
21. Favejee MM, Huisstede BM, Koes BW. Frozen shoulder: the effectiveness of conservative and surgical interventionssystematic review. Br J Sports Med. 2011;45:49-56.

22. Dodenhoff RM, Levy D, Wilson A, Copeland SA. Manipulation under anesthesia for primary frozen shoulder: effect on early recovery and return to activity. J Shoulder Elbow Surg. 2000;9(1):23-6.

23. Fox A, Board TN, Srinivasan MS. Improvement in shoulder function following manipulation for adhesive capsulitis: how long does it last? J Bone Joint Surg Br. 2006:88(Suppl 1):138-9.

24. Beaufils $P$, Prévot $N$, Boyer T, Allard M, Dorfmann H, Frank A, et al. Arthroscopic release of the glenohumeral joint in shoulder stiffness: a review of 26 cases. French Society for Arthroscopy. Arthroscopy 1999;15(1):49-55.

25. Jerosch J. 360 degrees arthroscopic capsular release in patients with adhesive capsulitis of the glenohumeral joint-indication, surgical technique, results. Knee Surg Sports Traumatol Arthrosc. 2001;9(3):178-86.

26. Pearsall AW 4th, Osbahr DC, Speer KP. An arthroscopic technique for treating patients with frozen shoulder. Arthroscopy. 1999:15(1):2-11.

27. Chen J, Chen S, Li Y, Hua Y, Li H. Is the extended release of the inferior glenohumeral ligament necessary for frozen shoulder? Arthroscopy. 2010;26(4):529-35.

28. Ogilvie-Harris DJ, Biggs DJ, Fitsialos DP, MacKay M. The resistant frozen shoulder. Manipulation versus arthroscopic release. Clin Orthop Relat Res. 1995;(319):238-48.

29. Harryman DT 2nd, Matsen FA 3rd, Sidles JA. Arthroscopic management of refractory shoulder stiffness. Arthroscopy. 1997;13(2):133-47.

30. Cinar M, Akpinar S, Derincek A, Circi E, Uysal M. Comparison of arthroscopic capsular release in diabetic and idiopathic frozen shoulder patients. Arch Orthop Trauma Surg. 2010;130(3):401-6.

31. Berghs BM, Sole-Molins X, Bunker TD. Arthroscopic release of adhesive capsulitis. J Shoulder Elbow Surg. 2004;13(2):180-5.

32. Elhassan B, Ozbaydar M, Massimini D, Higgins L, Warner JJ. Arthroscopic capsular release for refractory shoulder stiffness: a critical analysis of effectiveness in specific etiologies. J Shoulder Elbow Surg. 2010;19(4):580-7.

Received on 22/10/2012

Accepted for publication 25/12/2012

Conflict of interest: none.

Source of funding: none.

How to cite this article:

Fernandes MR. Arthroscopic treatment of refractory adhesive capsulitis of the shoulder. Rev Col Bras Cir. [periódico na Internet] 2014;41(1). Disponível em URL: http://www.scielo.br/rcbc

Address for correspondence:

Marcos Fernandes Rassi

E-mail: marcosombro@ig.com.br 